\title{
pH effect on the synthesis of different \\ size silver nanoparticles evaluated by DLS and their size-dependent antimicrobial activity
}

\author{
Efeito do $\mathrm{pH}$ na síntese de diferentes tamanhos \\ de nanopartículas de prata avaliados por EDL \\ e sua atividade antimicrobiana dependente do tamanho
}

\author{
Leiriana Aparecida Pinto Gontijo ${ }^{1}$, Ellen Raphael ${ }^{1,2}$, \\ Daniela Pereira Santos Ferrari ${ }^{1}$, Jefferson Luis Ferrari ${ }^{1}$, \\ Juliana Pereira Lyon ${ }^{1}$, Marco Antônio Schiavon ${ }^{1}$
}

\footnotetext{
${ }^{1}$ Grupo de Pesquisa em Química de Materiais - (GPQM), Departamento de Ciências Naturais, Universidade Federal de São João del-Rei, Campus Dom Bosco, Praça Dom Helvécio, 74, CEP: 36301-160, São João del-Rei, MG, Brazil.

${ }^{2}$ Escola Superior de Tecnologia, Engenharia Química, Universidade Estadual do Amazonas, Avenida Darcy Vargas, 1200, CEP: 69050-020, Manaus, AM, Brazil.

e-mail: leiriana@hotmail.com, eraphael@uea.edu.br, dapesantos@gmail.com,jeffersonferrari@gmail.com, julianalyon@ufsj.edu.br, schiavon@ufsj.edu.br
}

\begin{abstract}
This paper reports citrate-stabilized silver nanoparticles (AgNPs) synthesized by nitrate ion chemical reduction with sodium borohydride, at different pHs (2-9). The AgNPs synthesized by this method exhibited size distribution from 5 to $249 \mathrm{~nm}$, depending on $\mathrm{pH}$, as determined by dynamic light scattering, and morphology spherical, as determined by transmission electron microscopy. In $\mathrm{pH}$ range 3-7 occurred aggregation of the nanoparticles. The size distribution depending on $\mathrm{pH}$ was determined by dynamic light scattering. The zeta potential was determined, and the colloidal stability was correlated with nanoparticles aggregation at different pHs. The size-dependent antimicrobial activity was evaluated for two solutions, wherein both samples exhibited antimicrobial activity, although the smallest AgNPs without agglomeration have enhanced antimicrobial properties.
\end{abstract}

Keywords: Silver Nanoparticles, Zeta Potential, Dynamic Light Scattering, Size Distribution, Antimicrobial Activity.

\section{RESUMO}

Este trabalho relata nanopartículas de prata estabilizadas com citrato (AgNPs) sintetizadas pela redução química do íon nitrato com boro-hidreto de sódio, em diferentes pHs (2-9). As AgNPs sintetizadas por este método apresentaram distribuição de tamanho de 5 a $249 \mathrm{~nm}$ dependente do $\mathrm{pH}$, conforme determinado por espalhamento dinâmico de luz, além de morfologia esférica, conforme determinado por microscopia eletrônica de transmissão. Na faixa de $\mathrm{pH}$ de 3 a 7 ocorreu a agregação das nanopartículas. A distribuição de tamanho, dependendo do $\mathrm{pH}$, foi determinada por espalhamento dinâmico de luz. O potencial Zeta foi determinado e a estabilidade coloidal foi correlacionada com a agregação de nanopartículas em diferentes pHs. A atividade antimicrobiana dependente do tamanho foi avaliada para duas soluções, em que ambas as amostras exibiram atividade antimicrobiana, embora as menores AgNPs sem aglomeração apresentaram propriedades antimicrobianas melhores.

Palavras-chave: Nanopartículas de Prata, Potencial Zeta, Espalhamento Dinâmico de Luz, Distribuição de Tamanhos, Atividade antimicrobiana. 


\section{INTRODUÇÃO}

Metal nanoparticles have attracted great interest in several areas, such as chemistry, physics, biology, and materials engineering. Among noble-metal nanoparticles, silver nanoparticles (AgNPs), has been widely studied due to their different physical, electronic, mechanical and chemical characteristics, such as high surface area/volume ratio, which stands out because it is not found in conventional materials and allows unusual applications of these materials, such as consumables, including soaps, toothpaste, and textile industries [1-3].

The AgNPs can be synthesized by different methods, such as the chemical reduction of metal ions in aqueous solutions, with or without stabilizing [4], or using the thermal decomposition of metal compounds in organic solvents [5]. Each synthesis route leads to peculiarities in the results related to morphology and size, producing nanoparticles spherical, elliptical, cubic, cylindrical, in the form of discs, dendrites, rods or wires, with different size dispersions [5-7]. The process involving the reduction of silver salts in an appropriate medium has been reported in the literature using various reducing agents, such as sodium borohydride [8], hydrazine hydrate [9], sodium citrate [10], and ascorbic acid [11]. In a reducing environment, some syntheses use a surface stabilizer and other are based only on reducing $\mathrm{AgNO}_{3}$ with sodium borohydride $\left(\mathrm{NaBH}_{4}\right)$. In the case of routes without using surface stabilizer, smaller nanoparticles are formed, which are less stable over time [10-12]. The use of ligands allows obtaining larger nanoparticles; however, they are more stable over time [13-15]. The choice of a suitable ligand is extremely important for obtaining every type of nanoparticle [6]. Sodium citrate is the most commonly used stabilizer; it has the advantage of being compatible with biomolecules and can easily be exchanged on the other ligand [7]. The methods using sodium citrate are quite simple, effective, the synthesis is rapid, and is characterized by the appearance of a yellow color; however, one must take extreme care with the conditions because the AgNPs formed in this conditions, different from other stabilizers, are very unstable [2, 7].

Different routes presented in the literature show that the metallic AgNPs have different morphologies and sizes, being strongly influenced by synthesis route, as well as their final properties [3, 5, 16]. There are recent studies in the literature about $\mathrm{pH}$ and size-effect, which show that the dissolution of AgNPs depends on the medium [17, 18], and the nanoparticles size are directly affected by the $\mathrm{pH}$ adjusted, this $\mathrm{pH}$ influences in the size-effect can be observed by the colors, from colorless to yellow [19-21]. However, there no found studies reporting the use of the Dynamic Light Scattering (DSL) technique with Zeta potential measurements to evaluate this $\mathrm{pH}$ effect on the size and stability of nanoparticles formed by the sodium borohydride reduction method using sodium citrate as a stabilizing agent. So the DSL results of silver nanoparticles prepared with a very simple synthesis method, stabilized with citric acid, at different $\mathrm{pHs}$, correlating their aggregation with the Zeta potential, are discussed in the present study.

A common AgNPs application is because they have activity against Gram-positive and Gram-negative bacteria, viruses, yeasts and filamentous fungi. Studies on AgNPs have attracted great interest; one of the reasons for these studies is the increase in antibiotic-resistant bacteria [1, 4]. The AgNPs present a broadspectrum bactericidal action due to the presence of silver, which leads to numerous applications of this material. Furthermore, the relatively low cost of manufacturing these nanoparticles should be noted.

The antibacterial efficacy of these nanoparticles is another important focus in the studies on AgNPs, some papers reported the dependence of the bacterial activity with regard to the size of these nanoparticles $[22,23]$. In this work, AgNPs were prepared from aqueous silver nitrate $\left(\mathrm{AgNO}_{3}\right)$ solution using sodium borohydride $\left(\mathrm{NaBH}_{4}\right)$ as the reductant and sodium citrate $\left(\mathrm{Na}_{3} \mathrm{C}_{6} \mathrm{H}_{5} \mathrm{O}_{7}\right)$ as the stabilizer; the reduction method was used in aqueous media, as a simple route in the AgNPs preparation. Besides that, the influence of the $\mathrm{pH}$ was studied, and the antibacterial activity depending on the size of the Ag nanoparticles was evaluated against two different bacteria: Gram-negative (Escherichia coli) and Gram-positive (Staphylococcus aureus) and a fungus (Candida albicans).

\section{MATERIALS AND METHODS}

\subsection{Materials}

Silver nitrate $\left(\mathrm{AgNO}_{3}\right)$ and sodium borohydride $\left(\mathrm{NaBH}_{4}, 97 \%\right)$ were obtained from Sigma-Aldrich (St. Louis, MO, USA), sodium citrate $\left(\mathrm{Na}_{3} \mathrm{C}_{6} \mathrm{H}_{5} \mathrm{O}_{7}\right)$, nitric acid $\left(\mathrm{HNO}_{3}\right)$, and sodium hydroxide $(\mathrm{NaOH})$ were obtained from Synth. All of the chemicals were used without additional purification. Milli-Q grade deionized water (Millipore) was used for the preparation of the solutions. Two bacterial strains, one Gram negative, namely Escherichia coli ATCC 53338, another one Gram positive, namely Staphylococcus aureus ATCC 29373, and a fungus strain, Candida albicans ATCC 10231, obtained from the Oswaldo Cruz Foundation, 
were subjected to this analysis. The nutrient medium used was Sabouraud, from HiMedia Laboratories, with bacteriological agar as a solidifying agent.

\subsection{Synthesis of AgNPs}

The AgNPs synthesis was performed based on a previously reported method [24]. Silver nitrate $\left(\mathrm{AgNO}_{3}\right)$ were reduced via sodium borohydride $\left(\mathrm{NaBH}_{4}\right)$, to obtain metallic silver $\left(\mathrm{Ag}^{0}\right)$, according to reaction (1):

$\mathrm{AgNO}_{3}(\mathrm{aq})+\mathrm{NaBH}_{4}(\mathrm{aq})+3 \mathrm{H}_{2} \mathrm{O}(\ell) \rightarrow \mathrm{Ag}(\mathrm{s})+\mathrm{H}_{3} \mathrm{BO}_{3}(\mathrm{aq})+7 / 2 \mathrm{H}_{2}(\mathrm{~g})+\mathrm{NaNO}_{3}(\mathrm{aq})$

During the process, $\mathrm{Na}_{3} \mathrm{C}_{6} \mathrm{H}_{5} \mathrm{O}_{7}$ was used as an additive to prevent the aggregation of particles. In this way, $8.7 \mathrm{~mL}$ Milli-Q water was added to a beaker with $10 \mathrm{~mL}$ of $\mathrm{AgNO}_{3}\left(4.0 \times 10^{-4} \mathrm{M}\right)$ and $0.5 \mathrm{~mL}$ of $\mathrm{Na}_{3} \mathrm{C}_{6} \mathrm{H}_{5} \mathrm{O}_{7}\left(4.0 \times 10^{-2} \mathrm{M}\right)$. Then $0.8 \mathrm{~mL}$ of $\mathrm{NaBH}_{4}$ was added under stirring $\left(5.0 \times 10^{-2} \mathrm{M}\right)$ and the solution was kept stirring for $15 \mathrm{~min}$, controlling the $\mathrm{pH}$ in the range 2-9 as required, with $\mathrm{HNO}_{3}(0.1 \mathrm{M})$ and $\mathrm{NaOH}$ (0.1 M).

\subsection{Characterization of AgNPs}

UV-vis absorption spectra were acquired on a Shimadzu UV-2550 spectrophotometer. The absorption measurements were performed with $10 \mathrm{~mm}$ quartz cuvettes (Shimadzu) using air-saturated solutions at room temperature, in the range $200-600 \mathrm{~nm}$. The optical characterization was performed at room temperature and under ambient conditions without any post-preparative treatment to the as-prepared AgNPs.

The zeta potential $(\zeta)$ and the particle size distribution of the aqueous dispersions was determined by dynamic light scattering (DLS) using a Delsa Nano 2.31 apparatus from Beckman Coulter. DLS technique consists in the measurement of the time-dependent fluctuations in the intensity of light scattered by particles, which are in constant Brownian motion and relates this to the particle size; these stems from the fact that a small particle illuminated by a light source scatters light in all directions. Transmission electron microscopy (TEM) images of the AgNP samples were taking using a JEOL microscope JEM 2100 FEG-TEM operating at $200 \mathrm{kV}$. The as-prepared samples were diluted several times before dropping them onto ultrathin carboncoated copper grids of 400 mesh, the excess solvent being previously evaporated.

\subsection{Analysis of the antimicrobial activity of AgNPs}

The antimicrobial effect of two different AgNP solutions, prepared at $\mathrm{pH} 4$ and 9, on Gram-negative (Escherichia coli) and Gram-positive (Staphylococcus aureus) bacteria and on a fungus (Candida albicans) was investigated by the Zone of Inhibition (ZOI) in the disk diffusion test. The nutrient medium used was Sabouraud, which is composed of $10 \mathrm{~g} \mathrm{~L}^{-1}$ of peptone and $\mathrm{NaCl}$, and $5 \mathrm{~g} \mathrm{~L}^{-1}$ of yeast extract supplemented with $16 \mathrm{~g} \mathrm{~L}^{-1}$ of bacteriological agar as a solidifying agent.

Silver-impregnated disks were prepared by loading Whatman filter papers ( $5 \mathrm{~mm}$ diameter) with AgNP solutions. AgNP impregnated filter papers were left to dry. The bacterial suspension $(200 \mu \mathrm{L})$ was applied uniformly on the surface of a nutrient Sabouraud agar growth plate and the disks were gently placed on top of the agar. Plates with a clean filter paper, without AgNPs, were used as controls. The plates were incubated for $24-48 \mathrm{~h}$ at $37{ }^{\circ} \mathrm{C}$, after which digital images of the plates were captured and the inhibition zone surrounding the disks was determined.

\section{RESULTS AND DISCUSSION}

\subsection{Synthesis of Nanoparticles}

Chemical reduction of $\mathrm{AgNO}_{3}\left(4.0 \times 10^{-4} \mathrm{M}\right)$ was performed with $\mathrm{NaBH}_{4}\left(5.0 \times 10^{-2} \mathrm{M}\right)$ as reduction agent. Initially, the nucleation of nanoparticles occurred by means of an inducing process starting from a supersaturated solution forming AgNP cores. From the core formed the nanoparticles were grown by a diffusion process. Prior to the $\mathrm{NaBH}_{4}$ addition, $\mathrm{Na}_{3} \mathrm{C}_{6} \mathrm{H}_{5} \mathrm{O}_{7}\left(4.0 \times 10^{-2} \mathrm{M}\right)$ was added, as stabilizer agent, to prevent the AgNPs aggregating over time. Immediately after the reduction, the $\mathrm{pH}$ was controlled by dropping $\mathrm{HNO}_{3}(0.1 \mathrm{M})$ and $\mathrm{NaOH}(0.1 \mathrm{M})$, under stirring to obtain eight solutions at different $\mathrm{pH}$ values, then the stability study of AgNPs was conducted according to $\mathrm{pH}$ variation. Figure 1 shows AgNP solutions, prepared in a first moment, at $\mathrm{pH} 8.9+0.15,4.2+0.10$, and $2.3+0.32$, the yellow color of the solution at $\mathrm{pH} 8.9+0.15$ is characteristic of formation of AgNPs, whereas the case of solutions with $\mathrm{pH} 4.2+0.10$ and $2.3+0.32$, exhibiting gray coloring indicates AgNPs aggregation. 


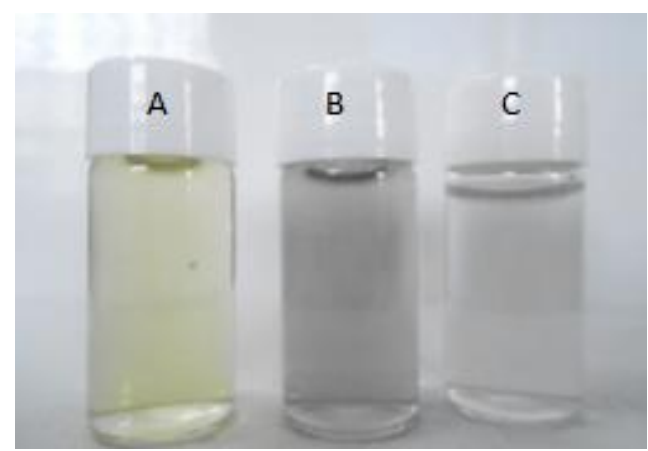

Figure 1: AgNP solutions prepared at $\mathrm{pH}=8.9+0.15$ (a), $4.2+0.10$ (b), and $2.3+0.32$ (c).

\subsection{Characterization by Spectroscopy}

UV-vis spectroscopy is a quick method for preliminary characterization of AgNPs that can be used to relate size parameters, shape, electron density, and other properties. These parameters are related to the optical absorption band, the maximum value of optical absorption $\left(A_{\max }\right)$, the wavelength of maximum absorption $\left(\lambda_{\max }\right)$ and the full width at half height (FWHH) [15]. Figure 2 shows the UV-vis spectra of AgNP samples prepared at different $\mathrm{pH}$ values.

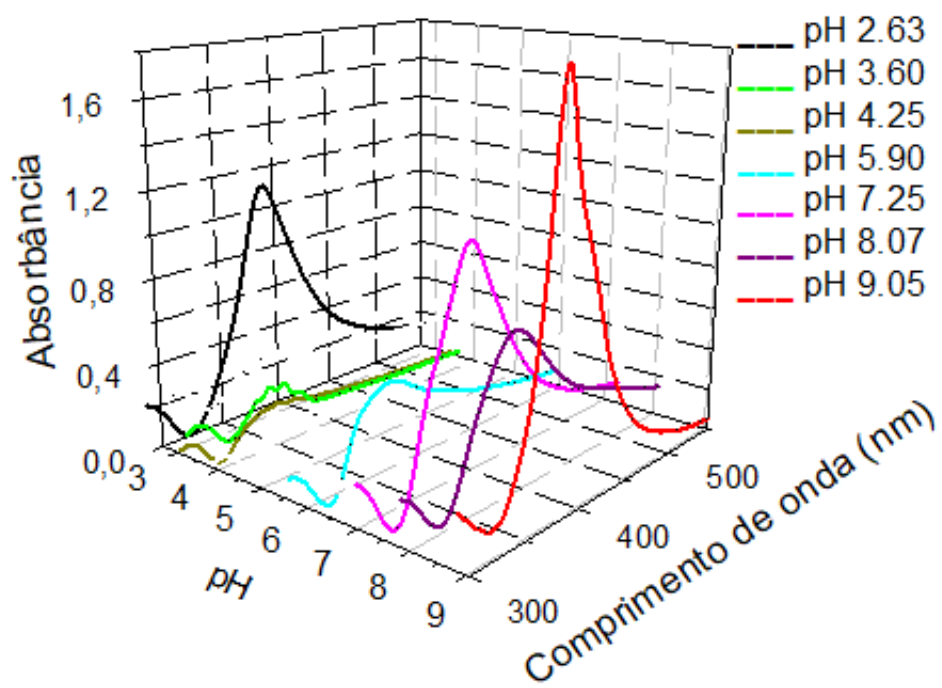

Figure 2: UV-vis spectra of AgNPs at different pHs.

The Figure 2 spectra shows a band around $390 \mathrm{~nm}$, which is due to AgNPs surface plasmon resonance $[24,25]$. The single band is an indication of the spherical shape of synthesized AgNPs, as spherical nanoparticles have only one oscillation mode of the surface plasmon [24]. The narrow FWHH obtained for solutions at $\mathrm{pH}$ less than 3 and greater than 7 indicates the presence of smaller nanoparticles with a size variation between $19.9 \mathrm{~nm}$ and $5 \mathrm{~nm}$. However, in the $\mathrm{pH}$ range of 3-7, the spectra set showed broader bands that may result from aggregation of the nanoparticles in solution [15, 25].

The as-produced sols, specifically the yellow-colored silver, produced a characteristic absorbance peak at $386 \mathrm{~nm}$, this wavelength of visible light creates a deep violet. From the UV-vis data, comparing the plasmon resonance wavelengths with the literature, the nanoparticles' size can be estimated as being from 10 to $20 \mathrm{~nm}$ for the silver sols $[24,25]$.

\subsection{Size distribution and Zeta potential}

To evaluate the average size, size distribution, and possible aggregation of AgNPs, the DLS technique was used. Figure 3 exhibits the graphs from diameter depending on the differential number (\%) at different $\mathrm{pH}$ values: $2.63,3.60,4.25,5.90,7.25,8.07$, and 9.05 , respectively. 

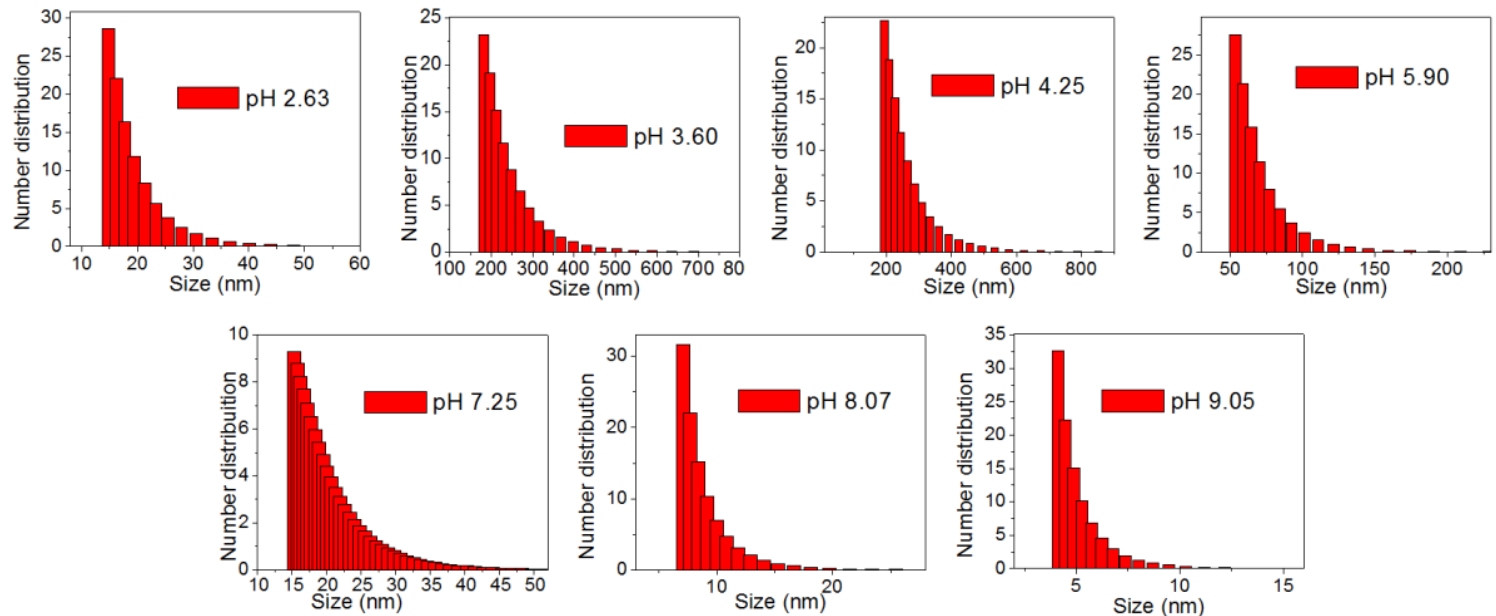

Figure 3: Diameter depending on the differential number (\%) at different $\mathrm{pH}$ values: 2.63 (a), 3.60 (b), 4.25 (c), 5.90 (d), 7.25 (e), 8.07 (f), and $9.05(\mathrm{~g})$.

The size comparison showed that the solutions with $\mathrm{pH}$ less than 3 and greater than 7 have smaller nanoparticles, whereas, in the $\mathrm{pH}$ range 3-7, the nanoparticles have a larger size, which is consistent with a possible aggregation of the nanoparticles. The $\mathrm{pH}$ is directly related to the stability of the nanoparticles. The change in $\mathrm{pH}$ can alter the double-layer properties that can directly influence the zeta potential of the system, making the chances of flocculation or coagulation, because each type of nanoparticles is stable near the isoelectric point. AgNPs exhibited an effective charge change in aqueous conditions, from positive (in low $\mathrm{pH}$ ) to negative (at high $\mathrm{pH}$ ), with an isoelectric point between them, in which it presented a smaller size value [26].

The nanoparticles sizes are smaller than some related in the literature [21, 27, 28]. AJITHA et. al. used the reduction method, $\mathrm{pH}$ between 6 and 12, however the smallest crystallite size was $14 \mathrm{~nm}$ [21]. The nanoparticles at $\mathrm{pH}$ less than 3 and greater than 7 are possibly less aggregated with a better colloidal stability of the solution. The colloidal stability of nanoparticles can be explained by a good adsorption of ligands on the surface of colloidal particles [29].

In this study, we used sodium citrate as a surface ligand, a salt from citric acid (2-hydroxy-1,2,3propanetricarboxylic acid), which is a weak organic acid containing three ionizable groups whose $\mathrm{p} K_{\mathrm{a}}$ values are 3.15, 4.77, and 6.40. Thus, below $\mathrm{pH} 3.15$, the most part of their acid groups are protonated, resulting in a charge increasingly close to zero as the medium becomes more protonated [29]. To ascertain the interaction of the sodium citrate with the AgNPs as well as the aqueous medium, the surface charge of the nanoparticle systems was determined using zeta potential measurements.

Table 1 presents the zeta potential values and the average size of AgNPs as a function of $\mathrm{pH}$.

Table 1. Zeta potential values and the average size of $\mathrm{AgNPs}$ as a function of $\mathrm{pH}$.

\begin{tabular}{c|c|c}
\hline $\mathbf{p H}$ & Zeta Potential $(\mathbf{m V})$ & Size $(\mathbf{n m})$ \\
\hline 2.63 & 12 & 18.7 \\
3.60 & -37 & 232 \\
4.25 & -66 & 249 \\
5.90 & -69 & 67.8 \\
7.25 & -66 & 19.9 \\
8.07 & -66 & 8.7 \\
9.05 & -61 & 5 \\
\hline
\end{tabular}


It is observed that the value of the zeta potential is more positive at more acidic $\mathrm{pH}$ due to dissociation of some $\mathrm{H}^{+}$and total protonation of the carboxyl groups of sodium citrate, and at higher $\mathrm{pH}$ values there is an increase of $\mathrm{OH}^{-}$ions in the dissociated solution and deprotonation of the carboxyl groups of citric acid gives a more negative zeta potential. As the lowest $\mathrm{p} K_{\mathrm{a}}$ of citric acid is 3.15, the zeta potential values are coherent because at this $\mathrm{pH}$ all ionizable groups are protonated. This corresponds to the isoelectric point, and the zeta potential should be zero [30].

A minimum zeta potential of more than $-30 \mathrm{mV}$ is required for good physical stability, and of more than $-60 \mathrm{mV}$ for excellent stability [31]. Thus, from the zeta potential results, the silver colloidal solutions at $\mathrm{pH}$ greater than 4.25 are supposed to be less stable than at $\mathrm{pH} 2.63$ or 3.6.

Figure 4 illustrates graphically the variation in the average size and zeta potential of AgNPs as a function of $\mathrm{pH}$.

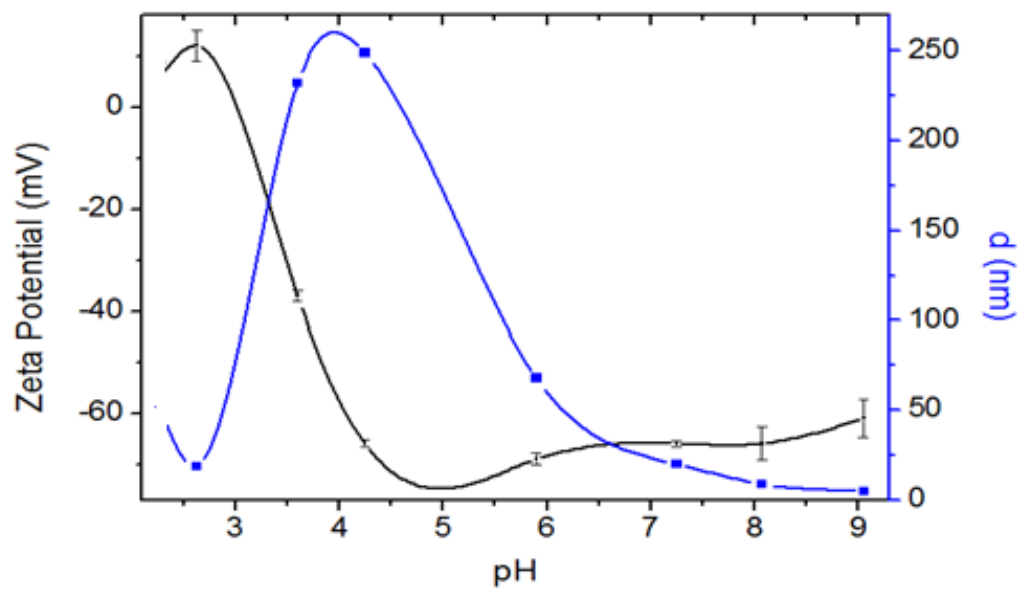

Figure 4: Variation in the zeta potential and average size of AgNPs as a function of $\mathrm{pH}$.

In the $\mathrm{pH}$ range of 3-6, the nanoparticles are less stable, with larger sizes due to AgNP aggregation. This aggregation is due to the presence of electrostatic interactions between partially ionized sodium citrate groups. At the $\mathrm{pH}$ range lower than 3 and greater than 7, the AgNPs are less aggregated, because in pH lower than 3 all groups are protonated, working against the electrostatic interaction. Conversely, at $\mathrm{pH}$ greater than 7, all groups are deprotonated favoring the repulsion between the nanoparticles, which discourages their aggregation.

\subsection{TEM Characterization}

The AgNPs shape and size were studied by TEM operating at $200 \mathrm{kV}$. Figure 5 shows TEM images of the AgNPs prepared at $\mathrm{pH} 4.25$ and 8.07. Samples prepared with $\mathrm{pH} 4.25$ and 8.7 were selected for TEM measurement, due to the fact that they presented in one case agglomerated nanoparticles and in the other values indicating non-agglomeration of the material. 

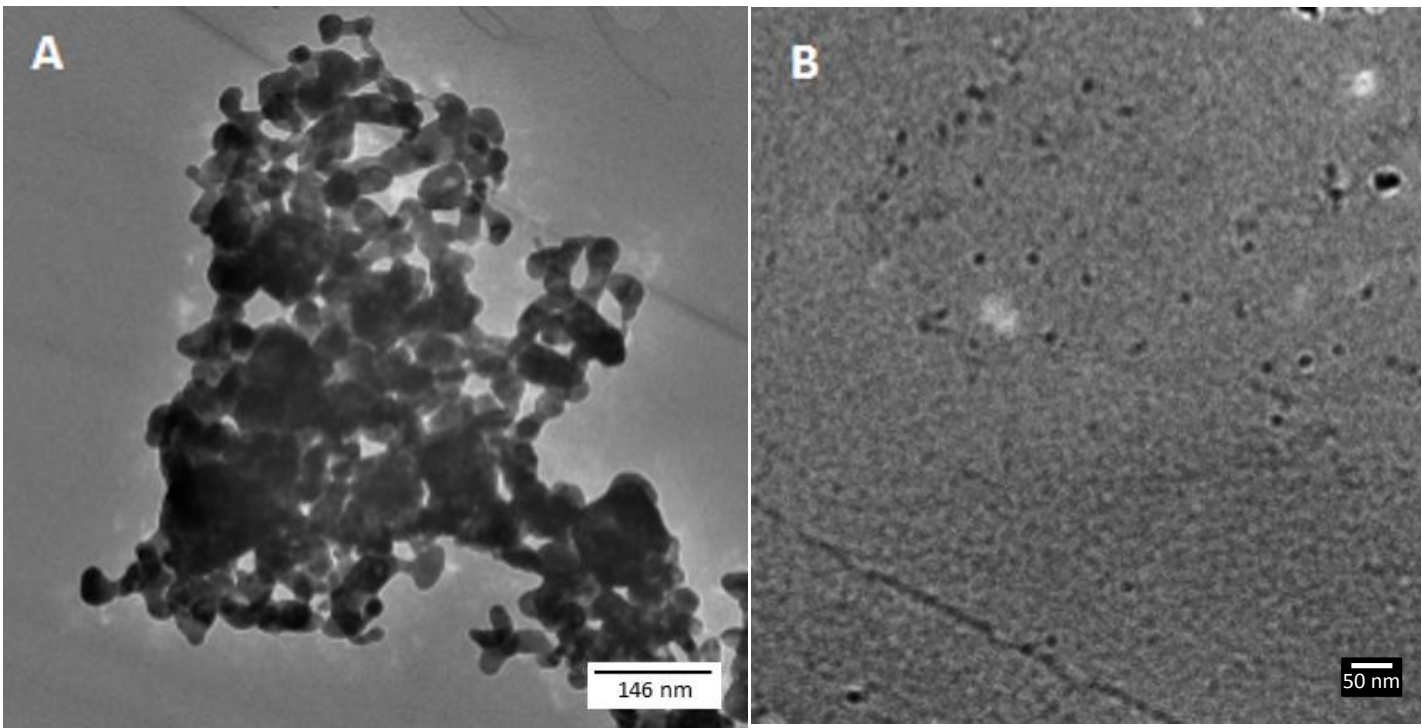

Figure 5: TEM images of AgNPs at $\mathrm{pH} 4$ (A) and $\mathrm{pH} 8$ (B).

The formation of roughly spherical nanoparticles can be confirmed by images in Figure 5, as observed in the UV-vis spectrum (Figure 4). The shape of the particles is not well defined but smaller particles have a spherical-like shape. The TEM image in Figure 5a shows nanoparticle agglomeration at $\mathrm{pH} 4.25$, as observed by DLS, producing agglomerates with average sizes up to $249 \mathrm{~nm}$, showing that in this condition the system is less stable. Figure 5b shows a TEM image of a sample obtained at $\mathrm{pH} \mathrm{8.07;} \mathrm{at} \mathrm{this} \mathrm{pH}$ the nanoparticles are nonagglomerated, yielding nanoparticles that are more stable in these conditions. This result is in agreement with the data from DSL and zeta potential measurements; besides, Bastús et al. showed the roughly spherical shape and the fact that AgNPs formed were more agglomerated in lower $\mathrm{pH}$, as in this case [32].

Thus, by using the techniques of characterization by UV-vis spectroscopy, DLS and zeta potential, and TEM, the AgNPs synthesis stabilized with sodium citrate was confirmed. The reaction conditions strongly influence the nanoparticles' shape and stability, and the $\mathrm{pH}$ was a determining factor in the stability and aggregation of nanoparticles.

\subsection{Effect of AgNPs on bacterial growth}

In this study, the size-dependent antimicrobial activity for AgNP samples was tested for three microorganisms. The AgNPs were prepared at $\mathrm{pH} 4.25$ and 9.05, and their activity was analyzed by measurements of the ZOI. By this method, a greater ZOI correlates with a greater activity of AgNPs.

Samples with extreme values were selected for antimicrobial activity measurements. Samples with $\mathrm{pH}$ 4.25 , with a reported size of $249 \mathrm{~nm}$, and a sample with $\mathrm{pH} 9.05$ with a size of $5 \mathrm{~nm}$ were selected. Table 2 summarizes the ZOI of disk diffusion tests of AgNP solutions prepared at $\mathrm{pH} 4.25$ and 9.05, against Gramnegative (Escherichia coli) and Gram-positive (Staphylococcus aureus) bacteria and a fungus (Candida albicans).

Table 2. The ZOI values for different microbial strains as a function of AgNP solutions' $\mathrm{pH}$.

\begin{tabular}{cccc}
\hline Microbial strain & Control & AgNPs $-\mathbf{p H} \mathbf{4}(\mathbf{m m})$ & AgNPs $-\mathbf{p H} \mathbf{9}(\mathbf{m m})$ \\
\hline Candida albicans & - & $0.233+0.06$ & $0.333+0.06$ \\
Staphylococcus aureus & - & $0.167+0.06$ & $0.333+0.06$ \\
Escherichia coli & - & $0.167+0.06$ & $0.333+0.11$ \\
\hline
\end{tabular}

The sample prepared at $\mathrm{pH} 4.25$ exhibited agglomerated nanoparticles as already discussed, while the sample prepared at $\mathrm{pH} 9.05$ exhibited smaller nanoparticles with no agglomeration. Both AgNP samples presented a small inhibition halo around the papers, proving that both samples had antibacterial activity. Bastús et al. also proved that at pH lower than 10, the AgNPs antibacterial effect is better 43 [30]. In contrast, Oukarroum et al. showed that the more acidic $\mathrm{pH}$ has a stronger cytotoxic effect on algal cells of $C$. acidophila 25 [18]. A quantitative analysis was performed by measuring in $\mathrm{mm}$ the ZOI around the papers. These results were obtained by subtracting the paper disk diameter from ZOI for all the microbial strains. No 
significant differences were observed in the antimicrobial effect between the microbial strains tested, the greater antimicrobial activity is noticed for small nanoparticles.

\section{CONCLUSIONS}

In this study, AgNPs were synthesized by a chemical reduction method and the effect of $\mathrm{pH}$ on the colloidal stability of these nanoparticles was evaluated. The $\mathrm{pH}$ influence in the formation of AgNPs is extremely important. It was possible to characterize the formation of AgNPs stabilized with sodium citrate by means of UV-vis spectra, which showed a single band at $390 \mathrm{~nm}$ due to the spherical morphology of the nanoparticles and the surface plasmon resonance effect. From the TEM images, it was possible to confirm the morphology of spherical AgNPs, as well as its state of aggregation at different $\mathrm{pH}$ values. Moreover, through the variation of the $\mathrm{pH}$, it was possible to observe a higher aggregation in the $\mathrm{pH}$ range between 3 and 7 . At a $\mathrm{pH}$ lower than 3 and higher than 7, it was observed that there was less aggregation. From this study, we can confirm that the stability of AgNPs is highly influenced by $\mathrm{pH}$. The synthesized AgNPs were found to have more antimicrobial potential than those described in earlier reports. The effect was more pronounced in smaller AgNPs obtained at higher $\mathrm{pH}$ values.

\section{ACKNOWLEDGMENTS}

The authors acknowledge the funding agencies CAPES, FAPEMIG and CNPq. This work is a collaborative research project of members of the Rede Mineira de Química (RQ-MG) supported by FAPEMIG (Project: CEX - RED-00010-14)

\section{BIBLIOGRAPHY}

[1] SHU, M., HE, F., LI, Z., et al., "Biosynthesis and Antibacterial Activity of Silver Nanoparticles Using Yeast Extract as Reducing and Capping Agents," Nanoscale Research Letters, n. 15v. 14, p. 9, 2020.

[2] XIE, Y., YE, R., LIU, H., "Synthesis of silver nanoparticles in reverse micelles stabilized by natural biosurfactant," Colloids and Surfaces A: Physicochemical and Engineering Aspects, v. 279, n. 1-3, pp. 175178, 2006.

[3] Adeleke OJo, O., Oyinloye, B.E., Busola Ojo, A., et al., "Green-route mediated synthesis of silver nanoparticles (AgNPs) from Syzygium cumini (L.) Skeels polyphenolic-rich leaf extracts and investigation of their antimicrobial activity," IET Nanobiotechnology, v. 12, n. 3, pp. 305-310, 2018.

[4] SURIATI, G., MARIATTI, J., AZIZAN, A., "Synthesis of silver nanoparticles by chemical reduction method: Effect of reducing agent and surfactant concentration," International Journal of Automotive and Mechanical Engineering, vol. 10, no. December, pp. 1920-1927, 2014.

[5] Varanda, L.C., SouZA, C.G.S., Moraes, D.A., et al., "Size and shape-controlled nanomaterials based on modified polyol and thermal decomposition approaches. A brief review," Annals of the Brazilian Academy of Sciences 91(4): e20181180, 2019.

[6] CHEN, Z., GAO, L., "A facile and novel way for the synthesis of nearly monodisperse silver nanoparticles," Materials Research Bulletin, vol. 42, no. 9, pp. 1657-1661, 2007.

[7] ŠILEIKAItĖ, A., ProsyČEVAS, I., PUIŠO, J., et al., "Analysis of Silver Nanoparticles Produced by Chemical Reduction of Silver Salt Solution," Materials Science (Medžiagotyra), vol. 12, no. 4, pp. 1392-1320, 2006.

[8] KUMAR, A., JOSHI, H., PASRICHA, R., et al., "Phase transfer of silver nanoparticles from aqueous to organic solutions using fatty amine molecules," Journal of Colloid and Interface Science, vol. 264, no. 2, pp. 396-401, 2003.

[9] PAL, A., SHAH, S., Devi, S., "Synthesis of Au, Ag and Au-Ag alloy nanoparticles in aqueous polymer solution," Colloids and Surfaces A: Physicochemical and Engineering Aspects, vol. 302, no. 1-3, pp. 51-57, 2007.

[10] LI, H., XIA, H., WANG, D., et al., "Simple synthesis of monodisperse, quasi-spherical, citrate-stabilized silver nanocrystals in water," Langmuir, v. 29, n. 16, pp. 5074-5079, 2013.

[11] Chaudhari, V.R., HARAM, S.K., KUlShreshtha, S.K., et al., "Micelle assisted morphological evolution of silver nanoparticles," Colloids and Surfaces A: Physicochemical and Engineering Aspects, vol. 301, no. 1-3, pp. 475-480, 2007.

[12] LIU, L., GAO, Z., JiAnG, B., et al., "Reversible Assembly and Dynamic Plasmonic Tuning of Ag Nanoparticles Enabled by Limited Ligand Protection," Nano Letters, p. acs.nanolett.8b02325, 2018.

[13] Skiba, M.I., Vorobyova, V.I., Pivovarov, A., et al., "Green Synthesis of Silver Nanoparticles in the 
Presence of Polysaccharide: Optimization and Characterization", Journal of Nanomaterials, v. 2020,10 p., ID 3051308, 2020.

[14] RyCEnga, M., CoBley, C.M., ZENG, J., et al., "Controlling the Synthesis and Assembly of Silver Nanostructures for Plasmonic Applications,” Chem Rev, v. 111, n. 6, pp. 3669-3712, 2012.

[15] HussaIn, J.I., TALIB, A., KUMAR, S., et al., "Time dependence of nucleation and growth of silver nanoparticles," Colloids and Surfaces A: Physicochemical and Engineering Aspects, v. 381, n. 1-3, pp. 2330, 2011.

[16] Gomathi, M., RAJKumar, P.V., PraKASAM, A., et al., "Green synthesis of silver nanoparticles using Datura stramonium leaf extract and assessment of their antibacterial activity," Resource-Efficient Technologies, v. 3, n. 3, pp. 280-284, Sep. 2017.

[17] PeretyazhKo, T. S., Zhang, Q., Colvin, V. L., "Size-Controlled Dissolution of Silver Nanoparticles at Neutral and Acidic pH Condition Kinectic and Size Changes," Environmental Science \& Technology, vol. 48, pp. 11954-11961, 2014.

[18] Oukarroum, A., SAMADANi, M., Dewez, D., "Influence of pH on the toxicity of silver nanoparticles in the green alga Chlamydomonas acidophila," Water, Air, and Soil Pollution, v. 225, n. 8, 2014.

[19] Alqadi, M.K., ABo NoqTAh, O.A., AlzOUBI, F.Y., et al., "PH effect on the aggregation of silver nanoparticles synthesized by chemical reduction," Materials Science-Poland, v. 32, n. 1, pp. 107-111, 2014.

[20] Nurfadhilah, M., Nolia, I., Handayani, W., et al., "The Role of pH in Controlling Size and Distribution of Silver Nanoparticles using Biosynthesis from Diospyros discolor Willd. (Ebenaceae)," IOP Conference Series: Materials Science and Engineering, v. 367, n. 1, 2018.

[21] AJITHA, B., ASHOK Kumar RedDy, Y., SREEDHARA REDDY, P., "Enhanced antimicrobial activity of silver nanoparticles with controlled particle size by $\mathrm{pH}$ variation," Powder Technology, v. 269, pp. 110-117, 2015 .

[22] Agnihotri, S., MUKHERJI, S., MUKHERJI, S., "Size-controlled silver nanoparticles synthesized over the range 5-100 nm using the same protocol and their antibacterial efficacy," RSC Advances, v. 4, n. 8, pp. 39743983, 2014.

[23] Shankar, S., ChORACHOO, J., JAISWAL, L., et al., "Effect of reducing agent concentrations and temperature on characteristics and antimicrobial activity of silver nanoparticles," Materials Letters, v. 137, pp. 160-163, 2014.

[24] CSAPÓ, E., PATAKFAlVI, R., HORNOK, V., et al., "Effect of pH on stability and plasmonic properties of cysteine-functionalized silver nanoparticle dispersion," Colloids and Surfaces B: Biointerfaces, v. 98, pp. 4349, 2012.

[25] McFarland, A. D., Haynes, C. L., Mirkin, C. A., et al., "Color My Nanoworld,” Journal of Chemical Education, v. 81, n. 4, p. 544A, 2004.

[26] OĆWIEJA, M., MORGA, M., "Electrokinetic properties of cysteine-stabilized silver nanoparticles dispersed in suspensions and deposited on solid surfaces in the form of monolayers," Electrochimica Acta, v. 297, pp. 1000-1010, 2019.

[27] AJITHA, B., Kumar REDDY, Y. A., REDDY, P. S., et al., "Role of capping agents in controlling silver nanoparticles size, antibacterial activity and potential application as optical hydrogen peroxide sensor," $R S C$ $A d v .$, v. 6, n. 42, pp. 36171-36179, 2016.

[28] Ginjupalli, K., Shaw, T., Tellapragada, C., et al., "Does the size matter? Evaluation of effect of incorporation of silver nanoparticles of varying particle size on the antimicrobial activity and properties of irreversible hydrocolloid impression material," Dental Materials, pp. 1-8, 2018.

[29] Chandran, P.R., NASEER, M., UDUPA, N., et al., "Size controlled synthesis of biocompatible gold nanoparticles and their activity in the oxidation of NADH," Nanotechnology, v. 23, n. 1, 2012.

[30] Al-GHAMdi, H.S., MAHMOUD, W. E., "One pot synthesis of multi-plasmonic shapes of silver nanoparticles,” Materials Letters, v. 105, pp. 62-64, 2013.

[31] CHOUdhary, R., KHURANA, D. KUMAR, A., et al., "Stability analysis of A12O3/water nanofluids," Journal Of Experimental Nanoscience, vol. 12, n. 1 pp. 140-151, 2017.

[32] Bastús, N., MerkoçI, F., PIELlA, J., et al., "Synthesis of Highly Monodisperse Citrate- Stabilized Silver Nanoparticles of up to $200 \mathrm{~nm}$ : Kinetic Control and Catalytic Properties," Chem. Mater., v. 26, n. MAY, p. 2836-2846, 2014. 


\section{ORCID}

Leiriana Ap. P. Gontijo Ellen Raphael

Daniela Pereira Santos

Jefferson Luis Ferrari

Juliana Pereira Lyon

Marco Antônio Schiavon

https://orcid.org/0000-0003-2119-0272

https://orcid.org/0000-0002-5617-8428

https://orcid.org/0000-0003-3647-4139

https://orcid.org/0000-0002-1239-0988

https://orcid.org/0000-0002-9016-8311

https://orcid.org/0000-0002-1553-5388 